\title{
As dimensões da integralidade no cuidado em saúde no cotidiano da Estratégia Saúde da Família no Vale do Jequitinhonha, MG, Brasil*
}

Selma Maria da Fonseca Viegas (a)

Cláudia Maria de Mattos Penna ${ }^{(b)}$

Viegas SMF, Penna CMM. The dimensions of the comprehensiveness on healthcare within the routine of the Family Health Strategy in the Jequitinhonha Valley, Minas Gerais, Brazil. Interface (Botucatu). 2015; 19(55):1089-100.

This was a qualitative holistic multiple case study based on comprehensive sociology of everyday life, with voluntary inclusion of 48 participants. It originated from a doctoral thesis. Its aim was to understand the dimensions of comprehensiveness present in healthcare, as conceptualized by professionals within the family healthcare teams and managers in the municipalities of the Jequitinhonha Valley, Minas Gerais, Brazil. Comprehensiveness of care was addressed in four dimensions: the whole being; comprehensive attendance for healthcare demands; integration of healthcare services; and intersectorality. The results show that it is not enough for professionals to have a watchful eye and be able to grasp users' needs. The population needs to have access to a system with comprehensive actions so that healthcare as a right for all can materialize.

Keywords: Comprehensive healthcare. Care. Family Health Strategy. Brazilian Health System.
Trata-se de estudo qualitativo de casos múltiplos holísticos, fundamentado na Sociologia Compreensiva do Cotidiano, originado de uma tese de doutorado, com a inclusão voluntária de 48 participantes. Teve como objetivo compreender as dimensões da integralidade presentes no cuidado em saúde na concepção de profissionais das equipes de Saúde da Família e de gestores de municípios do Vale do Jequitinhonha, Minas Gerais, Brasil. A integralidade foi abordada em quatro dimensões: a do ser integral; do atendimento integral às demandas em saúde; da integração dos Serviços de Saúde; da intersetorialidade. Os resultados indicam que não basta que os profissionais possuam um olhar atento e capaz de apreender as necessidades do usuário. É necessário que a população tenha acesso a um Sistema com ações integrais para a materialização da saúde como direito que é de todos.

Palavras-chave: Assistência integral à Saúde. Cuidado. Estratégia Saúde da Família. Sistema Único de Saúde.

\footnotetext{
* Elaborado com base na tese " $A$ integralidade no cotidiano da Estratégia Saúde da Família em municípios do Vale do Jequitinhonha - Minas Gerais", apresentada à Escola de Enfermagem da Universidade Federal de Minas Gerais, em 2010. Pesquisa aprovada pelo Comitê de Ética da Universidade Federal de Minas Gerais (COEP UFMG).

(a) Curso de Enfermagem - Área Saúde Coletiva, Universidade Federal de São del-Rei, campus Centro Oeste. Rua Sebastião Gonçalves Coelho, 400, sala 207, bloco A, Chanadour. Divinópolis, MG, Brasil. 35.501-296. selmaviegas@ ufsj.edu.br

(b) Departamento de Enfermagem MaternoInfantil e Saúde Pública, Escola de Enfermagem, Universidade Federal de Minas Gerais. Belo Horizonte, MG, Brasil. cmpenna@enf.ufmg.br
} 


\section{Introdução}

A integralidade e o cuidado apontam para as dimensões do viver humano que integram espaços, condições e expressões singulares que permitem reafirmar a complexa unidade humana. Nesse sentido, as atitudes, as ações e os fazeres dos profissionais de saúde devem valorizar os aspectos objetivos e subjetivos desse viver humano, respeitando o livre-arbítrio dos sujeitos na coprodução da saúde individual e coletiva.

A integralidade é um princípio doutrinário da política de Estado para a saúde, o Sistema Único de Saúde (SUS), que permite uma identificação dos sujeitos autônomos e livres, dignos de uma atenção à saúde qualificada e resolutiva. É um conceito que surgiu no contexto específico do SUS em 1988. É uma palavra que não existe no dicionário, constituiu-se descritor em Ciências da Saúde somente em 2014. Não há referência à palavra integralidade na Constituição da República de 1988, e sim ao atendimento integral no art. 198, inciso II, que prescreve que, no campo da saúde, haja "atendimento integral, com prioridade para as atividades preventivas, sem prejuízo dos serviços assistenciais" ${ }^{1}$ ( $p$. 133). Na Lei Orgânica da Saúde ${ }^{2}$ há uma única referência à integralidade no artigo $7^{\circ}$, inciso II, que determina que as ações devam ser realizadas "obedecendo ao princípio da integralidade de assistência, entendida como conjunto articulado e contínuo das ações e serviços preventivos e curativos, individuais e coletivos, exigidos para cada caso em todos os níveis de complexidade do sistema"2 (p. 3).

Destarte, a integralidade tem sido defendida como o eixo condutor dos processos de mudanças para uma ruptura de valores tradicionais na Saúde, como a fragmentação da atenção e do cuidado às pessoas.

Visando à atenuação da fragmentação da assistência, o trabalho em equipes multidisciplinares foi acertadamente traduzido no SUS como prioridade para a Atenção Primária à Saúde (APS) e se constituiu na estruturação da Estratégia Saúde da Família (ESF) com os profissionais: médico; enfermeiro; técnico de enfermagem; agentes comunitários de saúde (ACS); cirurgião-dentista e técnico/auxiliar de saúde bucal. Como, também, na formulação do Núcleo de Apoio à Saúde da Família (NASF), que atua de maneira integrada e apoia os profissionais da ESF; ou, mesmo, nos municípios que não possuem o NASF, pela atuação de profissionais pediatras, ginecologistas e clínicos em Unidades Básicas de Saúde (UBS). Dessa forma, "a ESF é um exemplo, local privilegiado de prática clínica, que permite atenção e acompanhamento continuado das pessoas, e que pode viabilizar uma necessária revolução contrária, como vem fazendo a tendência hegemônica biomédica"3 (p. 203).

Nessa conjuntura, a ESF visa à reorganização da APS de acordo com os preceitos do SUS, e é tida como estratégia de expansão, qualificação e consolidação da APS por favorecer uma reorientação do processo de trabalho com maior potencial: de aprofundar princípios, diretrizes e fundamentos desse nível de atenção, de ampliar a resolutividade e o impacto na situação de saúde das pessoas e coletividades, além de propiciar uma importante relação custo-efetividade 4 .

Se o fundamental é potencializar esforços que impulsionem mudanças em direção à construção de um novo paradigma no setor Saúde, o esclarecimento da construção da integralidade, em suas dimensões e no contexto da ESF, pode resultar numa importante sinergia em torno não apenas da Saúde da Família enquanto coordenadora do cuidado integral no contexto da família e da comunidade, mas com mudanças mais efetivas que atendam às necessidades de saúde da população e uma gestão pública mais comprometida com o bem saúde.

Considerando os princípios doutrinários do SUS como eixos dessas mudanças na construção de novos modos de produzir saúde, "o da universalidade nos impulsiona a construir o acesso para todos, o da equidade nos exige pactuar com todos o que cada um necessita, mas a integralidade nos desafia a saber e fazer o 'quê' e 'como' pode ser realizado em saúde para responder universalmente às necessidades de cada um" ${ }^{5}$ (p. 14).

Para responder às necessidades mediante as singularidades dos usuários, é mister o cuidado integral. Atribuem-se, à palavra cuidado, os significados de tomar conta, atitude, um ato de vida, no sentido de que representa uma variedade de atividades que visam manter, sustentar a vida e permitir continuar e reproduzir-se $\mathrm{e}^{6}$. O cuidado é visto como um conjunto de comportamentos e ações que envolvem: conhecimentos, habilidades e atitudes, intuição e pensamento crítico, realizados para com 
o ser cuidado, no sentido de promover, manter e/ou recuperar sua dignidade e totalidade humanas. Essa dignidade e totalidade englobam o sentido de integridade e a plenitude física, social, emocional, espiritual e intelectual nas fases do viver e do morrer, e constituem, em última análise, um processo de transformação de ambos, cuidador e ser cuidado.

Como a ESF utiliza tecnologias de cuidado complexas e variadas que devem auxiliar no manejo das necessidades de saúde de maior frequência e relevância em seu território de abrangência, observando critérios de risco, vulnerabilidade, resiliência e o imperativo ético de que toda demanda, necessidade de saúde ou sofrimento devem ser acolhidos, para que se atenda ao princípio da integralidade ${ }^{4}$, justificase a realização deste estudo.

Nesse contexto, questiona-se: Quais as dimensões da integralidade presentes no cuidado em saúde no cotidiano da ESF em municípios do Vale do Jequitinhonha, Minas Gerais, Brasil?

O estudo teve como objetivo compreender as dimensões da integralidade presentes no cuidado em saúde na concepção de profissionais das equipes de Saúde da Família e de gestores de municípios do Vale do Jequitinhonha.

\section{Métodos}

O estudo é de abordagem qualitativa, delineado pelo método de Estudo de Casos Múltiplos Holísticos $^{8}$, fundamentado no referencial teórico da Sociologia Compreensiva do Cotidiano ${ }^{9}$ originado de uma tese de doutorado ${ }^{10}$.

Fez-se a opção por lançar o olhar da sociologia compreensiva, que se ocupa em descrever "o vivido naquilo que é, contentando-se, assim, em discernir as visões dos diferentes atores envolvidos" 9 (p. 25). É necessário que haja um equilíbrio entre razão e sentimento para analisar um fenômeno. Portanto, a sociologia compreensiva é adequada para descrever os limites e a necessidade de situações e aspectos constitutivos da vida cotidiana, formada pelo sujeito e suas interações. Utilizou-se da análise de conteúdo ${ }^{11}$ para reunir os fragmentos do cotidiano da práxis, das experiências de vida e concepções dos profissionais e gestores para identificar conteúdos significativos para o objeto em estudo.No imbricamento dos referenciais metodológico e teórico utilizados frente ao objeto em estudo - a integralidade no trabalho cotidiano na ESF -, o cotidiano se estrutura em toda a amplitude do campo da saúde, seja em seu viés repetitivo ou em seu viés de ruptura e transformação. Isso só se torna possível a partir do momento em que enxergamos o cotidiano muito além das denominações genéricas, que o aproximam da ideia construída pelo senso comum e o descrevem como repetição, rotina ou banalidade. Passamos a enxergá-lo em todas as suas formas de apresentações, resgatando aspectos como imaginário e subjetividade ${ }^{12}$.

A proposta foi realizar estudo de caso individual em cada um dos três municípios situados no Vale do Jequitinhonha, Minas Gerais, Brasil: Diamantina (46.212 habitantes), Gouveia (11.915 habitantes) e Datas (5.418 habitantes) ${ }^{13}$; constituindo-se um estudo de casos múltiplos. A pesquisa inclui: sete equipes da ESF localizadas em seis UBS, as equipes de apoio e os gestores municipais. Elegeu-se como unidade única de análise "a integralidade no trabalho cotidiano em saúde", isto é, cada caso em particular consiste em um estudo "completo", no qual se procuram evidências convergentes ou divergentes com respeito aos fatos que detêm significados para compreensão dessa unidade de análise nos três cenários. A fim de atender à metodologia proposta, foi efetuada uma quarta análise, apresentada neste artigo, configurando a análise dos casos múltiplos holísticos.

Fundamentando-se nas evidências resultantes de estudos de casos múltiplos, em que é possível usar a replicação literal, as "conclusões analíticas que independentemente surgiram dos três casos foram mais contundentes do que aquelas que surgem apenas de um caso"8 (p. 75); e se pode chegar, neste estudo, "a conclusões comuns a partir dos três casos, estendendo de forma incomensurável a capacidade externa de generalização das descobertas no estudo"8 (p. 75).

Os participantes voluntários desta pesquisa, no total de 48, foram: médicos ( $M)$, enfermeiros (E), técnicos de enfermagem (TE), agentes comunitários de saúde (ACS), cirurgião-dentista (CD), auxiliar de saúde bucal (ASB), fisioterapeuta (F) e os gestores de cada município (SMS - secretários de saúde 
com acúmulo de função gerencial). Como critério de inclusão, estabeleceu-se uma atuação de, no mínimo, um ano no cargo de trabalho.

A pesquisa de campo, durante um período de oito meses, teve por base um levantamento de dados primários por meio de observação direta e de entrevistas a partir das seguintes questões: 1 "Fale-me da sua prática cotidiana na Estratégia Saúde da Família". 2 "O que você compreende por integralidade em saúde?" 3 "Como você percebe o desenvolvimento da integralidade nas ações da equipe de trabalho?" 4 "Você deseja acrescentar algo?" (Espaço aberto para o informante).

O registro da observação direta foi feito num diário de campo elaborado após cada período de observação, identificado como notas de observação (NO). Foi utilizado como entrada no campo de pesquisa e constitui um instrumento complementar na captação da realidade dos participantes da pesquisa e na corroboração dos dados das entrevistas, obtida pelo princípio da triangulação dos dados ${ }^{8}$.

A análise de dados foi feita com base no referencial de Bardin ${ }^{11}$, utilizando-se a técnica do emprego da Análise de Conteúdo Temática, ou seja, uma análise dos "significados".

A pesquisa foi desenvolvida segundo as diretrizes e normas da Resolução do Conselho Nacional de Saúde 196/96, revisada pela Resolução n 466, de 12 de dezembro de 2012. A coleta de dados iniciouse após a aprovação do projeto pelo Comitê de Ética da Universidade Federal de Minas Gerais. O anonimato dos participantes foi garantido por meio da adoção de siglas que identificam cada profissão, enumeradas sequencialmente, de acordo com a equipe e o profissional entrevistado.

\section{Resultados e discussão}

A integralidade foi abordada pelos participantes da pesquisa em quatro dimensões que configuram a categoria temática "As dimensões da integralidade no cuidado em saúde no cotidiano da Estratégia Saúde da Família", discutida neste artigo (Quadro 1).

Quadro 1. Categoria temática e as dimensões da integralidade em saúde

\begin{tabular}{|l|l|}
\hline \multicolumn{2}{|c|}{ Categoria temática: as dimensões da integralidade no cuidado em saúde no cotidiano da Estratégia Saúde da Família } \\
\hline $\begin{array}{l}\text { Dimensões da Integralidade } \\
\text { (Temas) }\end{array}$ & \multicolumn{1}{c|}{ Subtemas } \\
\hline 1a- Ser integral & $\begin{array}{l}\text { Considera a integralidade das pessoas, definindo o conceito de "um todo"; " "a pessoa"; um } \\
\text { "ser completo"; "o respeito à pessoa acima de qualquer coisa". }\end{array}$ \\
\hline $\begin{array}{l}\text { 2a- Atendimento integral às } \\
\text { demandas em saúde }\end{array}$ & As pessoas devem ser atendidas em suas necessidades de saúde. \\
\hline $\begin{array}{l}\text { 3a- Integração dos Serviços } \\
\text { de Saúde }\end{array}$ & $\begin{array}{l}\text { A integração e a organização dos serviços de saúde dependem de saberes de diferentes } \\
\text { disciplinas, da regionalização das Unidades na formação de um sistema de saúde local. }\end{array}$ \\
\hline 4a- Intersetorialidade & $\begin{array}{l}\text { As demandas podem ser de cunho intersetorial; a intersetorialidade como pilar fundamental } \\
\text { da integralidade. }\end{array}$ \\
\hline
\end{tabular}

Fonte: Elaborado pelas autoras, 2015.

A primeira dimensão da integralidade, caracterizada na expressão "olhar a pessoa", concretiza a abordagem do usuário como sujeito integrado à família, ao domicílio e à comunidade, ou seja, em sua vivência no mundo: 
"Integralidade em saúde é olhar a pessoa, o usuário no caso, paciente (entre aspas) como um todo: mente e corpo. Não é só olhar a questão da doença, do diabetes, da gripe. É olhar o paciente como um ser completo e que necessita de atenção, e que muitas vezes as doenças vêm de origem emocional". $\left(M_{1}\right)$

“Eu procuro sempre valorizar o paciente como ser humano, como pessoa [...] de colocar-me no lugar dele, ver que ele, às vezes, chega com carência, a gente precisa tratá-lo com mais cuidado, com delicadeza. Temos que valorizar o paciente e saber tratá-lo e respeitá-lo, acima de qualquer coisa, considerar suas necessidades, carências e tudo". $\left(\mathrm{ACS}_{21}\right)$

Integralidade é tratar a pessoa como ser humano "com mais cuidado e com delicadeza", valorizando e respeitando, acima de qualquer coisa, as suas necessidades, portanto, é cuidar do todo. Alguns estudiosos derivam cuidado do latim, usada num contexto de relações de amor e amizade. Outros derivam cuidado de cogitare, dando o sentido de pensar em, aplicar a atenção, aplicar o pensamento em alguma coisa.

Cura, como ser da presença, nas interpretações de Heidegger"14 (p. 262), "visava a conquistar os aspectos ontológicos adequados para o ente que nós mesmos somos e que chamamos de homem". Para isso, sua análise teve de seguir, desde o princípio, a direção do ponto de partida ontologicamente legado na definição tradicional do homem. Mas, no conceito ôntico, a cura pode ser compreendida, segundo Heidegger, como "cuidado" e "apreensão". Para o autor, isso quer dizer que "do ponto de vista ôntico, todos os comportamentos e atitudes do homem são dotados de cura e guiados por uma dedicação". Contudo, a condição existencial de possibilidade de cuidado como cura e dedicação deve "ser concebida como cura num sentido originário, ou seja, ontológico"14 (p. 265). Quando fala de cuidado, Heidegger sinaliza que é o fundamento para qualquer interpretação do ser humano e é somente a partir do cuidado essencial que o querer e o desejar emergem como realizações do humano.

Cuidado, para $\operatorname{Boff}^{15}$ (p. 89), influenciado pela leitura de Heidegger em Ser e Tempo, apresenta-se no sentido de "não se tratar de pensar e falar sobre o cuidado como objeto independente de nós. Mas de pensar e falar a partir do cuidado como é vivido e se estrutura em nós mesmos. Não temos cuidado. Somos cuidado". Para esse autor, isso significa que o "cuidado possui uma dimensão ontológica que entra na constituição do ser humano. Sem cuidado, deixamos de ser humanos"15 (p. 90).

No sentido dado por Boff'15 (p. 91), " cuidado significa então desvelo, solicitude, deligência, zelo, atenção, bom trato". Nesse sentido, a $\mathrm{ACS}_{21}$, a expressar sua noção de integralidade, menciona o respeito ao outro acima de qualquer coisa. Essa abertura para a compreensão do cuidado foi dada quando $\mathrm{ACS}_{21}$ falou sobre a integralidade, que é, em sua concepção, tratar o outro com mais cuidado e com delicadeza. Essa criatura chamada Homem, em uma transposição para o usuário nesse contexto, ficará, na interpretação da fábula do Cuidado ou Cura ${ }^{14}$, sob os cuidados de Cura, ou seja, dos cuidadores. Assim, considera-se que não podemos impor conceitos para a formulação das ideias das pessoas. Elas exprimem suas ricas experiências, reiteradas em seu cotidiano (NO).

Qual a imbricação desses termos cuidado/integralidade? A integralidade é abordada por diversos autores como: princípio, diretriz política, objetivo, estratégia, ideal, devir, bandeira de luta ou como uma "ação social de interação democrática entre sujeitos no cuidado, em qualquer nível de Serviços de Saúde" ${ }^{16}$ (p. 257-8). Já pela perspectiva dos usuários, a ação integral tem sido frequentemente associada ao tratamento digno, respeitoso, com qualidade, acolhimento e vínculo ${ }^{16}$.

Segundo Ayres ${ }^{17}$, são identificados quatro campos retóricos da integralidade: o eixo das necessidades, que diz respeito à qualidade e natureza da escuta, acolhimento e resposta às demandas da atenção à saúde; o eixo das finalidades, que se refere a graus e modos de integração entre as ações de promoção da saúde, prevenção de agravos, tratamento de doenças e sofrimentos, e recuperação da saúde/reinserção social; o eixo das articulações de graus e modos de ações interdisciplinares e intersetoriais para respostas efetivas às demandas em saúde; e o eixo das interações subjetivas, implicando a qualidade das mesmas. Esses campos retóricos da integralidade são corroborados nos resultados deste estudo. 
Ao narrarmos os sentidos e significados dessas palavras, podemos considerar que a "Integralidade do Cuidado" possui termos imbricados, que se completam e fazem sentido na abordagem dos participantes da pesquisa em sua duplicidade: aquele que cuida e aquele que recebe o cuidado. Portanto, não temos como falar de cuidado sem considerarmos a relação que se estabelece no ato de cuidar (NO), nem podemos cuidar de uma pessoa sem considerá-la integral em suas dimensões.

As noções de cuidado aqui adotadas estão fundadas nas proposições de que o cuidado transcende o âmbito técnico do atendimento (NO) ou do nível de atenção em saúde. O cuidado representa a materialidade das relações interpessoais que se estabelecem no ato ou na atitude (NO). Essa apreensão de cuidado articula-se intimamente à noção de integralidade, pois impõe um olhar ampliado sobre o homem, sua saúde e seu cuidado.

Cuidar de alguém implica atuar cautelosamente, com delicadeza, como $\mathrm{ACS}_{21}$ afirma, sempre que esse cuidado se fizer necessário. Portanto, da concepção ao morrer. Nessa amplitude do humano, SMS, acrescenta que se trata de um ser social, e só vendo-o nesse todo é que se pode oferecer-lhe uma saúde, integralidade da saúde:

\footnotetext{
"Integralidade pra mim seria atender a pessoa como um todo. Ver o ser humano como um todo. Igual, por exemplo, a pessoa chega aqui com um problema... com verminose, uma simples verminose. Então você vai lá. Ela tem problema social. Ela não tem casa, ela não tem um banheiro bem feito, ela tem esgoto a céu aberto. O pai não tem emprego, a mãe é uma alcoólatra. Então é um problema social! O que eles fazem hoje? Eles separam tudo. Você vai e pega aquela criança, pega aquela família, o SUS vai e dá remédio. Trata a verminose e daí a dois meses "tá" o problema aí de novo. Então, como que você vai trabalhar a integralidade no SUS, se você não trabalha a área social? Então eu entendo que a integralidade seria tratar o sujeito como um todo. É saber como estão as condições de vida dele, se ele tem emprego, se ele tem como sustentar a família, fazer um planejamento familiar com ele, dar educação para os filhos dele. Aí você poderia oferecer uma saúde. Para a pessoa não procurar a saúde somente quando está doente. É Posto de Saúde ou Posto da Doença?" (SMS $)$
}

Para a pessoa não procurar a saúde somente quando estiver doente, pois o SUS dá o remédio, mas o problema é social. O que significa dizer que não é possível pensar saúde e doença, por exemplo, em dissociação com nossas necessidades e limites existenciais. Infelizmente, as relações entre saúde e doença ainda permanecem atreladas a um imaginário positivista, que não consegue ultrapassar os limites de separação entre o físico, o emocional, o mental, o social e o espiritual do ser humano. Como trabalhar a integralidade no SUS se separamos tudo? Saúde não significa somente ausência de doença.

Nesse sentido, o cuidado integral ou holístico promove humanismo, saúde e qualidade de vida ${ }^{18}$. $\mathrm{Na}$ Constituição da República de $1988^{1}$ e na Lei Orgânica de Saúde², a saúde é conceituada como resultado das condições de vida das pessoas. Não é adquirida apenas com assistência médica, mas, sobretudo, pelo acesso das pessoas a: emprego, salário justo, educação, habitação, saneamento, transporte, alimentação, cultura, lazer, e a um sistema de saúde digno e de qualidade. Essa definição envolve reconhecer o ser humano como ser integral, e a saúde como qualidade de vida. Nesse sentido, o cuidado se dá com responsabilização, com a incorporação ao ato terapêutico da valorização do outro, respeitando sua visão de mundo, seu contexto social e sua dignidade. Cuidar para se ter qualidade de vida é, portanto, ser cúmplice das estratégias de promoção da saúde, prevenção de riscos e agravos, cura e reabilitação; e, assim, esses segmentos compõem um dispositivo maior, que é a integralidade em saúde.

Essa completude para se ter saúde está longe de ser o alcançado, ou pode não estar completa nunca, porque "inviabiliza sua realização como horizonte normativo, pois as normas associadas à saúde, ao se deslocarem os horizontes, precisarão ser reconstruídas constantemente"19 (p. 19).

Conforme o depoimento de $\mathrm{SMS}_{1}$, para se oferecer saúde, é preciso trabalhar a área social, já que as situações de vida e saúde divergem em cada caso e para cada ser, ao se considerar, além das condições de vida, a subjetividade. As demandas também podem ser de caráter mais abrangente, segundo os diversos níveis de assistência ou de cunho intersetorial, ultrapassando o poder resolutivo 
do Setor Saúde, o que concretiza, nessa realidade, a quarta dimensão dada à integralidade, que é a intersetorialidade.

A intersetorialidade implica incluir ações que ultrapassem os muros das unidades de saúde e atinjam o contexto histórico, social, cultural, político e econômico dos indivíduos ou coletivos, no sentido de promover a saúde dos mesmos. Para isso, articulações e arranjos podem ocorrer por meio de parcerias entre diferentes setores e segmentos sociais para a produção da saúde e promoção da qualidade de vida das pessoas e do coletivo, tomando como objeto: os problemas, as necessidades, os determinantes e os condicionantes de saúde ${ }^{20}$.

A reflexão de $\mathrm{SMS}_{1}$ aborda o processo saúde-doença de determinação social e leva à apreciação "é posto da saúde ou posto da doença?" Então, nessas palavras, está o significado de que nos dirigimos à anulação da diversidade qualitativa da experiência humana, por meio de uma assistência focada na doença. Categorias como saúde e doença só fazem sentido sobre o plano da experiência que é vivenciada, sentida e não limitada à objetividade ou racionalidade científica. Assim, quando falamos de adoecimento, estamos nos referindo a uma experiência de sofrimento e de limitação sentida por um ser vivo concreto e situado social e existencialmente. Além da experiência pessoal, o indivíduo atribui "significado" à doença. Até porque quem adoece, adoece como um todo, ou seja, uma dor repercute no corpo, na alma, na vida. Por isso, é patente a necessidade de trabalhadores sensíveis, com uma nova ética na saúde.

Assim, essa ética deve ser permeada por "uma poderosa sensibilidade estética, feita de vibrações e de emoções coletivas, ela repousa sobre uma concepção mais inteira do ser humano. Aquela onde o coração e a razão, o espírito e os sentidos se conjugam para elaborar uma construção sólida onde tudo, junto, faz corpo"22 (p. 205). Logo, saúde e doença são conceitos de valor e apontam para a necessidade de uma abordagem integrativa da equipe para dar respostas às questões relativas às necessidades das pessoas e do coletivo (NO).

O distanciamento do social indica uma via de desumanização das práticas de saúde. A população procura por práticas contra-hegemônicas que se voltem para o sujeito, sua realidade local e seu modo de se relacionar com o mundo e perceber a saúde-doença22. O papel do profissional de saúde é agir sobre o outro que se põe sob nosso cuidado. Mas é também ajudar os outros a se ajudarem. Estimular a capacidade de as pessoas enfrentarem problemas, a partir de suas condições concretas de vida ${ }^{23}$.

Por isso, o processo de trabalho dos profissionais da ESF deve ser fundamentado em atos que possam ser um veículo de empoderamento da população, segundo as necessidades em saúde do sujeito ou da família. "Traduzir as necessidades e demandas, ou seja, dar voz aos sujeitos pode ser uma das estratégias para se organizar as práticas de integralidade em saúde nos serviços públicos"22 (p. 285).

A organização das práticas de integralidade foi abordada pelos participantes da pesquisa na dimensão organizacional descrita como ainda muito falha:

“Eu acho que tem que ter uma integração de todos os setores em saúde. Mas isso é ainda muito falho, porque você procura trabalhar a forma que acha certa, que é humana, mas na maioria das vezes não temos apoio necessário. Vejo dificuldades de integração com as outras Unidades de Saúde. De pouco tempo pra cá tem mais integração com as outras equipes da ESF. Além das dificuldades na marcação das consultas [especializadas], porque as vagas são mínimas". $\left(\mathrm{ACS}_{22}\right)$

"É o indivíduo ter uma assistência completa nos níveis primário, secundário, terciário. Isso é ter integralidade. É a pessoa ter direito à assistência em todos os aspectos, em sua necessidade". $\left(E_{2}\right)$

"Como a palavra diz, integrar todos os problemas, todas as especializações. Enfim, fazer uma medicina social, pra gente orientar não só na saúde, como na doença. Assim eu entendo a integralidade". $\left(\mathrm{M}_{3}\right)$

Nos depoimentos fica claro o entendimento do direito à atenção à saúde em todos os aspectos, estar em todos os níveis de assistência conforme a necessidade do usuário, contemplando, assim, a segunda dimensão da integralidade, que trata do atendimento integral. 
Ao abordar as dificuldades na integração das Unidades de Saúde e as vagas limitadas para as consultas especializadas, a $\mathrm{ACS}_{22}$ discute a terceira dimensão da integralidade, que se refere à integração dos Serviços de Saúde cuja organização depende de saberes de diferentes disciplinas e da regionalização na formação de um Sistema de Saúde local.

O procedimento normativo como forma de apropriação do modelo ideal de uma rede regionalizada e hierarquizada, "embora possa ser visto como uma prática educativa, é apenas o exercício do poder de vedar o acesso aos Serviços de Saúde demandados. Ou seja, esse modo de proceder, além de obstruir o acesso, negando de fato o direito, corrói a legitimidade do SUS"24 (p. 373-4). O ponto crítico desse modelo ideal "é a hipótese de que traduza muito mais uma racionalidade médica, que busca ordenar em seu próprio modo os fluxos, do que as necessidades das pessoas. Ou que não leva em conta, de modo abrangente, as necessidades das pessoas, o que pode contradizer a ideia de integralidade" 24 (p. 373-4).

Nos relatos, foram reveladas as fronteiras ou os horizontes que os informantes retratam como noções de integralidade adquiridas cotidianamente no contexto da ESF no Vale do Jequitinhonha. Esses resultados indicam que a integralidade vem sendo incorporada à consciência crítica dos profissionais de saúde nos três cenários da pesquisa. No entanto, não basta que esses profissionais possuam um olhar atento e capaz de apreender as necessidades do usuário se a população não tem acesso a um Sistema com ações integrais. Muitas vezes, acontece apenas a resolução imediata do problema que levou o usuário à consulta, e não um atendimento composto por procedimentos preventivos e curativos que visem suprir as necessidades pertinentes à sua saúde (NO). É preciso fazer medicina social.

Foi compreensível que a prática da integralidade não se traduz apenas no desenvolvimento de procedimentos ou rotinas capazes de identificar e oferecer ações curativas, mas, também, as preventivas, que geralmente não são solicitadas diretamente pelas pessoas que procuram pelos Serviços de Saúde. Para o atendimento integral, precisa-se compreender o contexto de vida do indivíduo que busca cuidado, e adotar um olhar que identifique as necessidades preventivas e assistenciais do usuário no contexto familiar e comunitário (NO).

Porém, aparece a dificuldade de enquadrar em palavras a noção de integralidade, dar forma ao que diz conhecer e que na vivência se concretiza: "Eu acho importante que, por exemplo, nas visitas domiciliares, fiquemos atentos àquelas pequenas coisas dos pacientes, saber ouvi-lo" $\left(\right.$ ACS $\left._{32}\right)$.

Nesse fragmento, percebemos que é expressa a noção de integralidade a partir da prática, o "como" no fazer cotidiano onde se manifestam pilares que sustentam o princípio: "saber ouvir, estar atento às pequenas coisas dos pacientes".

O depoimento engloba o ato de ouvir o usuário de uma forma límpida, do jeito que ele quer ser ouvido, e o respeito por sua pessoa numa visão totalizante - social, biológica e psicológica. É uma abordagem aberta, natural, não diretiva, sem forçar a comunicação, sem planejamento prévio e sem perguntas invasoras, em que o foco é escutar e observar as pequenas coisas. "Compreender é o ser existencial do próprio poder-ser da presença de tal maneira que, em si mesmo, esse ser abre e mostra a quantas anda seu próprio ser. Trata-se de apreender ainda mais precisamente a estrutura desse existencial" ${ }^{14}$ (p. 200), pois entende-se que o ser-presença se manifesta nos relatos e a quantas ele encaminha seu próprio ser profissional (NO).

Segundo Maffesoli ${ }^{21}$ (р. 67), "ser atento aos mistérios do ser é reconhecer o que, nos fenômenos sociais, elabora-se aquém ou além da simples consciência racional".

Nesse sentido, gerir o trabalho em saúde rumo à integralidade da atenção e do cuidado em saúde requer "uma reflexão crítica acerca das fragmentações presentes nas práticas individuais dos profissionais e os modos de sua organização nos serviços de saúde" 25 (p. 24).

A integralidade, a universalidade e a equidade, em muitos relatos, se conformam como princípios em interseção, mas a integralidade para $\mathrm{ACS}_{21}$ ainda não foi alcançada, pois ainda não alcançamos o "ser" tratado como "pessoa": "Integralidade, eu acho que ainda não tem, eu acho que é a forma de tratar o paciente como pessoa mesmo. Mas a gente faz o possível. O que está a nosso alcance, a gente faz" $\left(\mathrm{ACS}_{21}\right)$.

Compreendendo, sobretudo, que o que significa integralidade, para $\mathrm{ACS}_{21}$, é objeto ontologicamente distinto da prática que se submete à quantificação de procedimentos realizados. 
Impõe-se, portanto, a valorização dessa percepção, entendendo-a, não como subjetividade descontextualizada, como o querem fazer crer perspectivas idealistas, mas como sinalização de experiências complexas, materializadas nas relações estabelecidas com os profissionais e usuários, determinadas pelo distanciamento e por práticas fragmentadas em saúde, em que o foco é a doença. Ao expressar que integralidade é "a forma de tratar o paciente como pessoa", a ACS aborda as interfaces entre os dois planos - o subjetivo e o objetivo -, a materialidade a que se relaciona 0 adoecimento no aspecto formal do atendimento ao físico, o que distancia o sujeito ao invés de incluílo, ao não considerar suas necessidades e demandas que podem ultrapassar a abordagem física/ biológica. Essa interação profissional/usuário, "ser tratado como pessoa", pode desempenhar papel decisivo no processo de produção do cuidado integral em saúde.

Contudo, mais do que definições formais, a integralidade requer uma compreensão dos desafios que se colocam no presente e no futuro, que transcendem o campo de atuação profissional na ESF, e as políticas sociais estabelecidas com finalidade nas ações coletivas (NO), pois, conforme mensagens explícitas dos participantes do estudo, a integralidade vai muito além de seu radical integral.

\section{Considerações finais}

No Vale do Jequitinhonha, a integralidade em saúde foi apresentada sob significados que compõem suas dimensões: cuidar da pessoa conforme sua necessidade, em um atendimento integral e intersetorial; sua concretização depende da organização dos serviços e das práticas em saúde, da definição de políticas de saúde e sociais de forma integrada. Essas dimensões são essenciais para a materialização da saúde como direito e como bem diante das demandas, que devem ser ouvidas e atendidas na operacionalização dos Serviços de Saúde.

No âmbito da saúde coletiva, a integralidade compreende uma pluralidade de concepções, ações e atitudes que não se restringe apenas a um princípio do SUS, noção ou conceito coletivo. Mas amplia-se em um olhar para o sujeito-usuário dentro de uma lógica de atenção que considere essas dimensões, idealizadas e vivenciadas cotidianamente no terreno prático da assistência à saúde.

A integralidade e o cuidado em saúde são tarefas intersetoriais e só podem ser pensadas quando o nível primário consegue se articular adequadamente, em forma de rede, com os outros níveis de atenção à saúde e com os demais setores governamentais e não governamentais, para garantir e proteger a saúde como direito social instituído.

Assim sendo, a integralidade constitui um elemento central para a consolidação de um modelo de saúde que incorpore, de forma mais efetiva, a universalidade, a equidade no atendimento às pessoas para alcançar ações resolutivas em saúde.

Dessa forma, cabe-nos o exercício do aprendizado constante, de saber lidar com o embate cotidiano entre essas posições discursivas e ideológicas na compreensão da integralidade. Os resultados apontam que é preciso equipar o olhar para essa dimensão ampliada, extremamente fluida e móvel da integralidade, apreensível apenas em suas cristalizações, na forma de situações concretas, vividas e compartilhadas. São situações em que o cálculo racional entra nesse fazer cotidiano permanente, segundo a compreensão exposta pelos informantes, mas pode ser refeito ou se perde para uns, quando aceitamos a subjetividade como uma abertura para enxergar o outro. São situações, portanto, carregadas de um inapreensível que nos convoca permanentemente a olhar, das mais variadas formas e nos mais variados tempos, um mundo de estar-junto cheio de delicadezas: de sofrimentos, queixas, murmúrios, que se interpõem entre o eu e o outro, e que não obedecem a uma ordem na vida cotidiana.

Desse modo, "talvez seja preciso deixar que o eu e, naturalmente, o eu crítico, se dissolva, para melhor ouvir a sutil música nascente, para melhor dar conta da profunda mudança que se opera sob os nossos olhos" 26 (p. 113). Portanto, vamos equipar nosso olhar, "ouvir o mato $\operatorname{crescer"9}^{9}$ (p. 22), para deveras engendrar a integralidade, elemento central para a consolidação de um modelo de qualidade de vida para atender ao direito à saúde, que é de todos. 


\section{Colaboradores}

Selma Maria da Fonseca Viegas trabalhou na concepção, na pesquisa, na análise, na interpretação dos dados, na redação final e na revisão crítica do manuscrito. Cláudia Maria de Mattos Penna trabalhou na revisão crítica e na aprovação da versão para submissão à publicação.

\section{Referências}

1. Constituição 1988. Constituição da República Federativa do Brasil. Brasília (DF): Senado Federal; 1988.

2. Lei no 8.080, de 19 de setembro de 1990. Dispõe sobre as condições para a promoção, proteção e recuperação da saúde, a organização e o funcionamento dos serviços correspondentes, e dá outras providências. Diário Oficial da União. 19 Set 1990.

3. Tesser CD, Luz MT. Racionalidades médicas e integralidade. Cienc Saude Colet [Internet]. 2008 [acesso 2013 Jun 9]; 13(1):195-206. Disponível em: http://www. scielosp.org/scielo.php?script=sci_arttext\&pid=\$1413-81232008000100024\&lng =en

4. Ministério da Saúde. Gabinete do Ministério da Saúde. Portaria n 2.488, de 21 de outubro de 2011. Aprova a Política Nacional de Atenção Básica, estabelecendo a revisão de diretrizes e normas para a organização da Atenção Básica, para a Estratégia Saúde da Família (ESF) e o Programa de Agentes Comunitários de Saúde (PACS) [Internet]. Brasília (DF): MS; 2011 [acesso 2012 Maio 22]. Disponível em: http://portal.saude.gov.br/portal/ arquivos/pdf/portaria_2488_21-out-11_politica_atencao.pdf

5. Ayres JRCM. Organização das ações de atenção à saúde: modelos e práticas. Saude Soc [Internet]. 2009 [acesso 2012 Maio 20]; 18(2):11-23. Disponível em: http://www.scielo. $\mathrm{br} / \mathrm{pdf} / \mathrm{sausoc} / \mathrm{v} 18 \mathrm{~s} 2 / 03 . \mathrm{pdf}$

6. Colliere MF. Promover a vida. Abecassis MLB, tradutora. 4a ed. Lisboa: Lidel; 1999.

7. Waldow VR. Cuidado humano: o resgate necessário. Porto Alegre: Sagra-Luzzatto; 1998.

8. Yin RK. Estudo de caso: planejamento e métodos. Grassi D, tradutor. 3a ed. Porto Alegre: Bookman; 2005.

9. Maffesoli M. O conhecimento comum: compêndio de sociologia compreensiva. Trinta AR, tradutor. São Paulo: Brasiliense; 1988.

10. Viegas SMF. A integralidade no cotidiano da Estratégia Saúde da Família em municípios do Vale do Jequitinhonha - Minas Gerais [tese]. Belo Horizonte (MG): Escola de Enfermagem, Universidade Federal de Minas Gerais; 2010.

11. Bardin L. Análise de conteúdo. Reto LA, Pinheiro A, tradutores. São Paulo: Edições 70; 2011.

12. Maffesoli M. A contemplação do mundo. Porto Alegre: Artes e Ofícios; 1995.

13. Instituto Brasileiro de Geografia e Estatística. Estimativas da população para $1^{\circ}$ de julho de 2008 [Internet]. [acesso 2009 Ago 29]. Disponível em: http://www.ibge.gov.br/home/

14. Heidegger M. Ser e tempo. Cavalcante MS, tradutora. 8a ed. Petrópolis: Vozes; 1999.

15. Boff L. Saber cuidar: ética do humano, compaixão pela terra. 5a ed. Petrópolis: Vozes; 1999.

16. Pinheiro R. Integralidade em saúde. In: Pereira IB, Lima JCF, organizadores. Dicionário da educação profissional em saúde. 2a ed. Rio de Janeiro: EPSJV; 2008. p. 255-62. 
17. Ayres JRCM. O cuidado e o espaço público da saúde: virtude, vontade e reconhecimento na construção política da integralidade. In: Pinheiro R, Silva Júnior AG, organizadores. Cidadania no cuidado: o universal e o comum na integralidade das ações de saúde. Rio de Janeiro: IMS, Cepesc-UERJ; 2011. p. 27-44.

18. Acioli S. Os sentidos de cuidado em práticas populares voltadas para a saúde e a doença. In: Roseni P, Mattos RA, organizadores. Cuidado: as fronteiras da integralidade. Rio de Janeiro: Hucitec, Abrasco; 2004. p. 187-203.

19. Ayres JRCM. O cuidado, os modos de ser (do) humano e as práticas de saúde. Saude Soc [Internet]. 2004[acesso 2012 Maio 20]; 13(3):16-29. Disponível em: http://www.scielo.br/pdf/sausoc/v13n3/03.pdf

20. Silva KL, Rodrigues AT. Ações intersetoriais para promoção da saúde na Estratégia Saúde da Família: experiências, desafios e possibilidades. Rev Bras Enferm [Internet]. 2010 [acesso 2014 Ago 22]; 63(5):762-9. Disponível em: http://www.scielo.br/scielo. php?script=sci_arttext\&pid=S0034-71672010000500011\&lng $=$ en

21. Maffesoli $M$. Le réenchantement du monde: une éthique pour notre temps. Paris: Éditions de La Table Ronde; 2007.

22. Lacerda A, Valla VV. Um outro olhar sobre a construção social da demanda a partir da dádiva e das práticas de saúde. In: Pinheiro R, Mattos RA, organizadores. Construção social da demanda: direito à saúde, trabalho em equipe, participação e espaços públicos. Rio de Janeiro: Cepesc-UERJ, Abrasco; 2005. p. 279-91.

23. Campos CEA. O desafio da integralidade segundo as perspectivas da vigilância da saúde e da saúde da família. Cienc Saude Colet [Internet]. 2003 [acesso 2012 Mar 02]; 8(2):569-84. Disponível em http://www.scielo.br/scielo.php?script=sci arttext\&pid=\$1413-81232003000200018\&lng =pt\&nrm=iso

24. Mattos RA. Repensando a organização da rede de serviços de saúde a partir do princípio da integralidade. In: Roseni P, Mattos RA, organizadores. Razões públicas para a integralidade em saúde: o cuidado como valor. Rio de Janeiro: Cepesc-UERJ, Abrasco; 2007. p. 369-83.

25. Pinheiro R, Guizardi FL, Machado FRS, Gomes RS. Demanda em Saúde e direito à Saúde: liberdade ou necessidade? Algumas considerações sobre os nexos constituintes das práticas de integralidade. In: Roseni P, Mattos RA, organizadores. Construção social da demanda: direito à saúde, trabalho em equipe, participação e espaços públicos. Rio de Janeiro: Cepesc-UERJ, Abrasco; 2005. p. 11-31.

26. Maffesoli M. Elogio da razão sensível. Stuckenbruck ACM, tradutor. Petrópolis: Vozes; 1998. 
Viegas SMF, Penna CMM. Las dimensiones de la integralidad en el cuidado de la salud en el cotidiano de la Estrategia Salud de la Familia en la región del Vale do Jequitinhonha, estado de Minas Gerais, Brasil. Interface (Botucatu). 2015; 19(55):1089-100.

Se trata de un estudio de casos múltiples holístico, cualitativo, basado en la Sociología Comprensiva del Cotidiano, originado en una tesis de doctorado, con la inclusión voluntaria de 48 participantes. Su objetivo fue entender las dimensiones de la integralidad presentes en el cuidado de la salud en la concepción de profesionales de los equipos de Salud de la Familia y de gestores de municipios de la región de Vale do Jequitinhonha, Estado de Minas Gerais, Brasil. La integralidad se abordó en cuatro dimensiones: la del ser integral, la de la atención integral a las demandas de salud, la de la integración de los Servicios de Salud, la de la inter-sectorialidad. Los resultados indican que no basta que los profesionales tengan una mirada atenta y capaz de captar las necesidades del usuario. Es necesario que la población tenga acceso a un sistema con acciones integrales para la materialización de la salud como un derecho que es de todos.

Palabras clave: Asistencia integral a la Salud. Cuidado. Estrategia Salud de la Familia. Sistema Único de Salud.

Recebido em 01/09/14. Aprovado em 31/12/14. 